\title{
THE USE OF IRRADIATED EVAPORATED MILK IN INFANT FEEDING
}

\author{
Bir \\ RICHARD W. B. ELLIS, M.A., M.D., F.R.C.P. \\ Assistant Physician for Children's Diseases, Guy's Hospital, and Physician, \\ The Infants Hospital, Vincent Square, London
}

Although the incidence of rickets in England has been greatly reduced in recent years, mild cases are still seen too frequently even amongst infants attending infant welfare centres. This may be due either to the mother's failure to give the additional vitamin $\mathrm{D}$ that has been prescribed, or to insufficient amounts of vitamin D having been prescribed. If therefore any form of 'fortified' vitamin D milk were available at an economic price which could safely be relied on to prevent infantile rickets in artificially fed babies and could be given over long periods without ill effect, it would clearly have a valuable place in infant feeding. During the past fifteen years several types of fortified milk have been produced, though not all on a commercial basis. Examples are milk from cows fed with irradiated yeast, milk from irradiated cows, liquid and dried milk to which vitamin D concentrate has been added, and liquid, evaporated and dried milk which has been subjected to direct irradiation. Their relative values have been reviewed by Jeans (1936), who stresses the difficulties of comparing animal and human reactions to vitamin $\mathrm{D}$ and of accurate control of human experiments. A further source of error lies in the different methods of assay used by different workers. It is proposed here to consider only irradiated evaporated milk in relation to the prophylaxis and cure of infantile rickets.

After the discovery that the vitamin D content of foodstuffs could be greatly increased by exposure to ultra-violet light (Steenbock and Black, 1924 ; Hess and Weinstock, 1924), Steenbock and Daniells (1925) applied the principle to liquid milk. In succeeding years many experimental and clinical studies have appeared in the American and German literature with regard to the antirachitic properties of irradiated milk. Although the first clinical application was made by Cowell (1925) in England, and subsequent reports (Watson, Finlay and King, 1929 ; Nabarro and Hickman, 1929) have been favourable, the use of irradiated milk for infant feeding has attracted relatively little attention in this country.

At the present time three firms are producing irradiated evaporated milk in the British Isles on a commercial basis, and though none of them has put 
forward any extravagant claims for the value of irradiation, it seems highly desirable that information should be available with regard to the reliability or otherwise of these products in the prevention of rickets.

\section{Present investigation}

In order to assess the prophylactic value of the milk, a group of normal infants was observed over periods of from three to six months, between October and April, during which time the irradiated milk served as the sole source of oral vitamin D. It was not, of course, possible to exclude all exposure to sunlight during the period of study, since the infants were being treated in their homes, but as all were living in London and the period of observation was limited to the six darker months of the year, it was felt that the conditions would provide a sufficiently severe test of a normal full-term infant's requirements. The more rigorous criteria recommended by Eliot and Powers (1935), by which both prematures and deeply pigmented infants are included in the group studied, were not fulfilled, since it was felt that the diet must first be shown to be sufficient in vitamin content for the normal infant before extending its use to those in whom the requirements will be greater.

The curative properties of the milk were tested in seven infants suffering from active rickets. Six of these patients were kept in hospital throughout the whole period of study.

Milk.-The brand of milk used in this investigation was a commercial preparation sold under the name of Irradiated Carnation Milk, an unsweetened evaporated milk having a caloric value of 53 per fluid ounce ; one part of evaporated milk to one-and-a-half parts of water represents reconstituted cow's milk. The manufacturer's assays showed an average of 165 international units of vitamin D per reconstituted quart (40 fluid ounces). It should be emphasized, however, that the present study was not concerned with the per unit protective value of evaporated milk (in which case confirmatory assays of every batch of milk would be necessary, owing to the known difficulties of exact and permanent standardization of the irradiation process), but with determining if the milk as marketed did in fact have an appreciable antirachitic value and if so whether or not it was an adequate protection against rickets when given as the sole source of vitamin $\mathrm{D}$ in the diet, and used over a considerable period.

The manufacture includes evaporation at $135^{\circ} \mathrm{F}$., homogenization and irradiation by the Steenbock process, using the carbon-arc lamp. In practice it was found that the milk was in fact successfully homogenized, there being little or no separation of the fat on standing, and that no unpleasant taste had been given to the milk (as is liable to occur with more prolonged irradiation).

It is not proposed to discuss the merits of evaporation of milk as such for infant feeding, since it is generally agreed that a reliable unsweetened evaporated milk provides a satisfactory basis for infants' formulas, that it has the advantage of being a clean milk which can safely be kept in the unopened tin, and that the evaporation process probably renders the curd more readily digestible than that of fresh cow's milk. 


\section{Normal group (prophylaxis)}

Twenty normal full-term infants, who had received no previous antirachitic treatment, were examined clinically and radiologically for evidence of rickets, and in the absence of this were given irradiated evaporated milk in formulas appropriate for their age, the younger infants receiving not more than one-third of the total calories of the feed as added carbohydrate. They were in addition given orange juice and after the age of six months crusts and cereal; subsequently minced lean meat and potatu were added.

The ages at the onset of treatment varied from six weeks to ten months, fourteen of the infants being under six months of age. Twelve of the infants, attending the Barley Mow welfare centre, lived in a poor district in North Lambeth ; the remaining eight all lived in London, but were on the whole from rather better homes. At the end of three months' treatment, the infants were re-examined clinically and radiologically for evidence of rickets, and again at the end of treatment if this fell within the experimental period (October to April). With one exception (a female infant who weighed $17 \mathrm{lb}$. at one year, after four months' treatment), the infants gained well on the irradiated milk and took it without difficulty after the first few days. Comparison with a control group of artificially fed infants receiving corresponding cow's milk or dried milk formulas with the addition of six drachms of cod-liver oil emulsion (50 per cent. cod-liver oil) daily showed no significant differences in weight increment or incidence of infection. The groups are, however, too small for emphasis to be placed on this. Although the original number of babies given irradiated milk was considerably more than twenty, there was no case in which the mother defaulted owing to dissatisfaction with the feeding.

Results.-Of the twenty patients, one showed evidence of mild active rickets both radiologically and clinically (beading and flaring of ribs and slight bowing of tibiae) after three months' treatment ; this infant was five months old when treatment was started. Two infants showed radiological evidence of healed rickets after three months. These were aged seven weeks and three months respectively at the beginning of treatment. As the original x-rays in all cases had shown no signs of disease, this suggests that both had developed slight rickets during the earlier period of treatment, the condition then healing spontaneously. Four patients showed clinical signs suggesting rickets (bossing of skull, widely patent fontanelle, delayed dentition, and beading of ribs) after three to six months' treatment, but no radiological changes. Several authors (Hess and Lewis, 1933 ; Davidson et al., 1937) have commented on this discrepancy between clinical and radiological evidence of rickets, and many are inclined to regard radiology as the final test. Indeed, ' antirachitic beading, of the ribs has been attributed to an excess of vitamin D. The remaining patients in this series appeared normal.

In addition to the experimental period, several patients were kept for considerably longer periods on irradiated milk (in five cases for as long as eighteen months to two years). In none of these were ill effects attributable to excess of irradiated milk observed. From the extensive experience of its 
use by American observers it appears improbable that the pathological changes described in animals following excessive irradiation are at all likely to occur in human infants taking the commercial preparations of irradiated milk at present available (Hess and Lewis, 1932).

\section{Rachitic group (curative properties)}

Seven infants suffering from active rickets who had had no previous antirachitic therapy, were treated in hospital on a diet in which the irradiated milk provided practically the sole source of vitamin D. They were kept in the ward throughout the whole period of treatment, without exposure to ultraviolet light, with the exception of case 7, who was treated for two weeks (during November) in the home conditions in which the rickets had developed. In addition to the irradiated milk the diet consisted of orange juice (or fresh orange), cereal or porridge, bread, sugar and small amounts of lean beef or mutton and potato. The milk was given by cup as full-strength reconstituted milk, and in the concentrated form spread on bread or poured over the cereal or orange. In every case, the infants had been described by the parents as 'not liking milk' or difficult to feed, and most of them took one to two weeks to become used to taking more than eight to ten ounces of reconstituted milk in the day. After this time their average intake was in each case from twenty to twenty-five ounces a day, though considerable daily variation occurred.

Table 1 gives a summary of the cases. It will be seen that one infant was eight months old on admission, five were between one and two years old, and one was aged two years and four months. All came from very poor homes, the father being unemployed in six out of the seven cases. It is highly probable that the previous diet was deficient in calcium as well as vitamin $D$, at least in the case of the older children, and this should be borne in mind in assessing the response to treatment.

Biochemical investigations.-Serial estimations were made of serum calcium, plasma inorganic phosphorus and phosphatase during treatment in four cases (table 2). Case 1 showed a fall in phosphatase from 139 units before treatment to $14 \cdot 1$ after nine weeks' treatment, the calcium-phosphorus product rising from 26.4 to 57.8 over the same period (see fig. 1). Case 2 showed a somewhat anomalous initial value for the calcium-phosphorus product $(50.9)$, falling to 36 after one week's treatment and subsequently rising to 50.7 after five weeks' treatment. The phosphatase was little raised at onset ( 25 units), falling to $15 \cdot 2$. In case 3 the calcium-phosphorus product rose in six weeks from $37 \cdot 2$ to $44 \cdot 7$, and the phosphatase fell from 45 to 16.9 units. The estimations on case 7 were begun after the infant had received irradiated milk for two weeks ; the calcium-phosphorus product rose from 31.2 to 38.8 and the phosphatase fell from 26 to 10 units after a further three weeks' treatment. The biochemical findings therefore generally confirm the progress of healing under treatment with irradiated milk observed in the x-rays (see below).

Radiological investigations and results.-In each case, $x$-rays showed evidence of active rickets before treatment, though in case 4 (fig. 5) there was 
IRRADIATED EVAPORATED MILK IN INFANT FEEDING 299

\begin{tabular}{|c|c|c|c|c|c|c|c|}
\hline 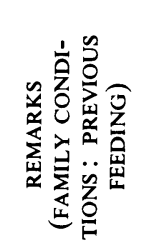 & \multicolumn{7}{|c|}{ 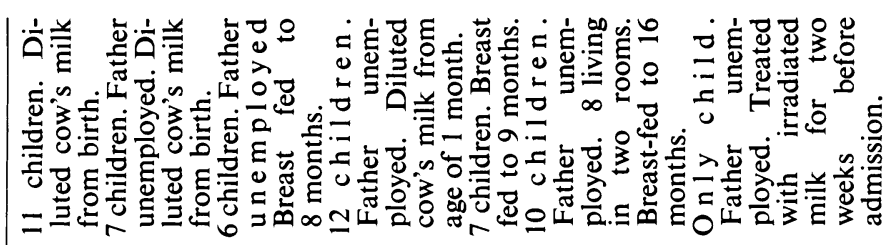 } \\
\hline 它岂 & $\vec{\sim}$ & $\bar{N}$ & 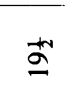 & $\tilde{N}$ & $\tilde{\lambda}$ & $\vec{N}$ & $\overrightarrow{\mathbb{N}}$ \\
\hline 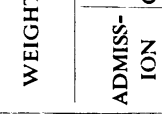 & $\vec{d}$ & $\frac{-1+}{N}$ & $\stackrel{\infty}{\infty}$ & 苍 & $\tilde{\sim}$ & $\overrightarrow{\mathbf{C}^{+}}$ & $\overrightarrow{\bar{N}}$ \\
\hline 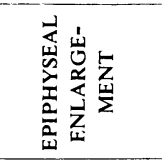 & 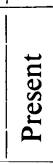 & 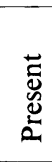 & 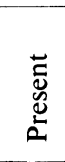 & 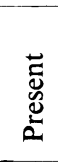 & 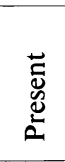 & 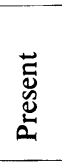 & 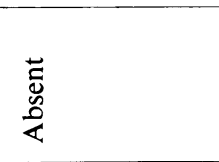 \\
\hline 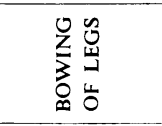 & 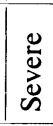 & 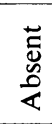 & 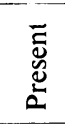 & 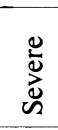 & 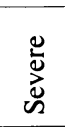 & 苂 & 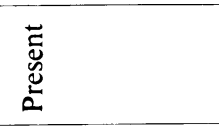 \\
\hline 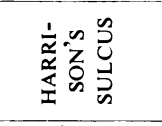 & 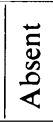 & 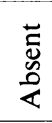 & 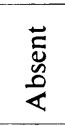 & 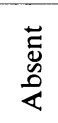 & 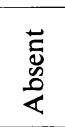 & 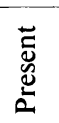 & 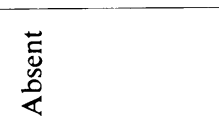 \\
\hline 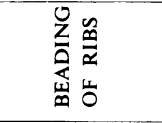 & 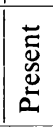 & 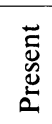 & 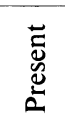 & 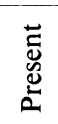 & 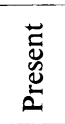 & 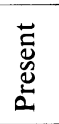 & $\begin{array}{l}\text { 苟 } \\
\text { 峞 }\end{array}$ \\
\hline 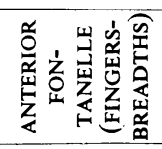 & $\begin{array}{l}0 \\
\ddot{y} \\
0 \\
0\end{array}$ & - & $\nabla$ & $N$ & $\begin{array}{l}\overrightarrow{0} \\
0 \\
0\end{array}$ & - & $\nabla$ \\
\hline 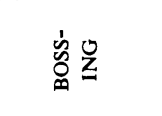 & 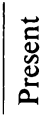 & 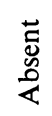 & 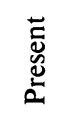 & 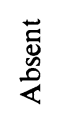 & 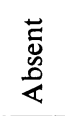 & 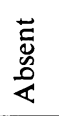 & 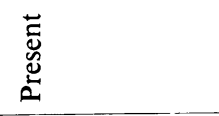 \\
\hline 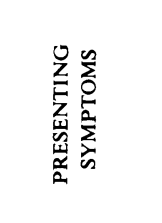 & 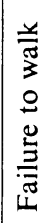 & 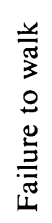 & 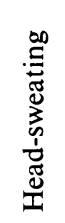 & 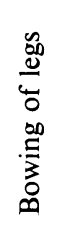 & 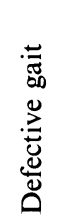 & 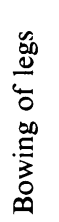 & 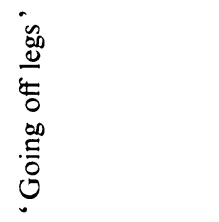 \\
\hline 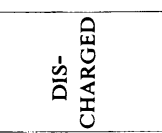 & 官 & 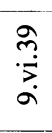 & 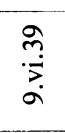 & $\begin{array}{l}\stackrel{9}{+} \\
\stackrel{5}{5} \\
\text { in }\end{array}$ & 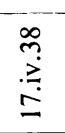 & 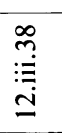 & $\begin{array}{l}\infty \\
m \\
: \\
0 \\
0 \\
0\end{array}$ \\
\hline 安畩 & $\mid \begin{array}{c}\infty \\
\vdots \\
\vdots \\
\infty \\
\infty\end{array}$ & $\underset{\substack{p \\
\infty}}{\stackrel{\infty}{\infty}}$ & 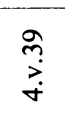 & 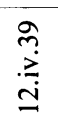 & $\begin{array}{l}\infty \\
\vdots \\
\vdots \\
\stackrel{\sim}{\sim}\end{array}$ & $\stackrel{\infty}{:}$ & $\underset{\substack{\infty \\
\dot{x} \\
\infty}}{\infty}$ \\
\hline 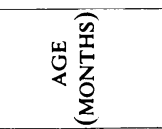 & $\infty$ & $m$ & $\infty$ & $=$ & $\bar{\sim}$ & $=$ & $\underline{0}$ \\
\hline 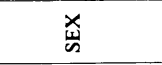 & 4 & $\Sigma$ & $\Sigma$ & 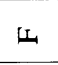 & L & $\Sigma$ & $\Sigma$ \\
\hline 晏 & 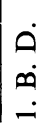 & $\begin{array}{l}\dot{a} \\
\dot{n} \\
\dot{d}\end{array}$ & $\begin{array}{l}\dot{3} \\
\dot{\alpha}\end{array}$ & $\begin{array}{l}\dot{a} \\
\dot{\sigma}\end{array}$ & $\begin{array}{l}\dot{0} \\
\dot{-} \\
\dot{n}\end{array}$ & $\begin{array}{l}\dot{x} \\
\dot{<} \\
\dot{b}\end{array}$ & $\begin{array}{l}\dot{3} \\
\dot{4}\end{array}$ \\
\hline
\end{tabular}


TABLE 2

\begin{tabular}{|c|c|c|c|c|c|}
\hline CASE & DATE & $\begin{array}{c}\text { SERUM } \\
\text { CALCIUM } \\
\text { (MGM. PER } \\
100 \text { C.C.) }\end{array}$ & $\begin{array}{c}\text { PLASMA } \\
\text { INORGANIC } \\
\text { PHOSPHORUS } \\
\text { (MGM. PER } \\
100 \text { c.C.) }\end{array}$ & $\begin{array}{c}\text { Ca X P } \\
\text { PRODUCT }\end{array}$ & $\begin{array}{l}\text { PHOSPHATASE } \\
\text { (UNITS) }\end{array}$ \\
\hline 1 B.D. & $\begin{array}{c}29 . i i i .39 \\
19 . i v .39 \\
21 . i v .39 \\
26 . i v .39 \\
5 . v .39 \\
11 . v .39 \\
18 . v .39 \\
26 . v .39 \\
31 . v .39\end{array}$ & $\begin{array}{r}8.8 \\
9.0 \\
- \\
9.4 \\
9.6 \\
9.4 \\
9.6 \\
9.6 \\
11 \cdot 8\end{array}$ & $\begin{array}{r}-3 \cdot 0 \\
3 \cdot 3 \\
-4 \cdot 7 \\
4 \cdot 9 \\
5 \cdot 2 \\
6 \cdot 0 \\
5 \cdot 2 \\
4 \cdot 9\end{array}$ & $\begin{array}{l}26 \cdot 4 \\
29 \cdot 7 \\
-\overline{44 \cdot 2} \\
47 \cdot 0 \\
48 \cdot 9 \\
57 \cdot 6 \\
49 \cdot 9 \\
57 \cdot 8\end{array}$ & $\begin{array}{r}139 \cdot 0 \\
59 \cdot 7 \\
50 \cdot 0 \\
51 \cdot 8 \\
38 \cdot 0 \\
32 \cdot 0 \\
17 \cdot 6 \\
11 \cdot 8 \\
14 \cdot 1\end{array}$ \\
\hline 2 B.P. & $\begin{array}{l}\text { 11.v.39 } \\
18 . v .39 \\
26 . v .39 \\
13 . v i .39\end{array}$ & $\begin{array}{r}10 \cdot 4 \\
10 \cdot 0 \\
9 \cdot 8 \\
10 \cdot 8 \\
\end{array}$ & $\begin{array}{l}4 \cdot 9 \\
3 \cdot 6 \\
3 \cdot 9 \\
4 \cdot 7\end{array}$ & $\begin{array}{l}50 \cdot 9 \\
36 \cdot 0 \\
38 \cdot 2 \\
50 \cdot 8\end{array}$ & $\begin{array}{l}25 \cdot 0 \\
21 \cdot 9 \\
16 \cdot 4 \\
15 \cdot 2\end{array}$ \\
\hline 3 R.W. & $\begin{array}{c}\text { 4.v.39 } \\
11 . v .39 \\
18 . v .39 \\
26 . v .39 \\
31 . v .39 \\
13 . v i .39\end{array}$ & $\begin{array}{r}9 \cdot 3 \\
9 \cdot 0 \\
10 \cdot 2 \\
9 \cdot 5 \\
9 \cdot 3 \\
10 \cdot 4\end{array}$ & $\begin{array}{l}4 \cdot 0 \\
4 \cdot 6 \\
4 \cdot 2 \\
4 \cdot 4 \\
4 \cdot 2 \\
4 \cdot 3\end{array}$ & $\begin{array}{l}37 \cdot 2 \\
41 \cdot 4 \\
42 \cdot 8 \\
41 \cdot 8 \\
39 \cdot 1 \\
44 \cdot 7\end{array}$ & $\begin{array}{l}45 \cdot 0 \\
14 \cdot 1 \\
20 \cdot 3 \\
16 \cdot 1 \\
25 \cdot 6 \\
16 \cdot 9\end{array}$ \\
\hline 7 A.W. & $\begin{array}{c}9 . x i .38^{*} \\
22 . x i .38 \\
6 . x i i .38\end{array}$ & $\begin{array}{l}7 \cdot 8 \\
8 \cdot 1 \\
9 \cdot 7\end{array}$ & $\begin{array}{l}4 \cdot 0 \\
3 \cdot 9 \\
4 \cdot 0\end{array}$ & $\begin{array}{l}31 \cdot 2 \\
31 \cdot 6 \\
38 \cdot 8\end{array}$ & $\begin{array}{l}26 \cdot 0 \\
16 \cdot 0 \\
10 \cdot 0\end{array}$ \\
\hline
\end{tabular}

* After two weeks' treatment.

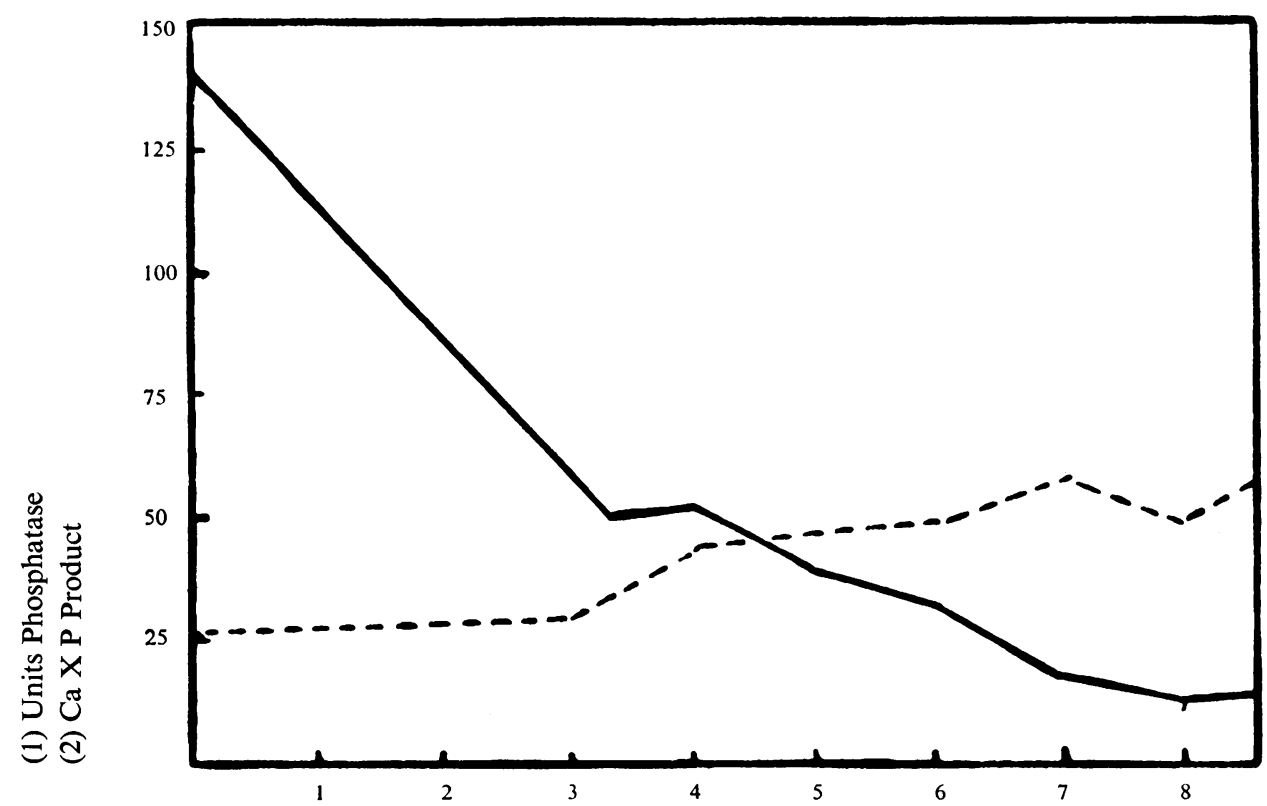

9 Weeks' Treatment

FIG. 1.-Showing effect of treatment on phosphatase (unbroken line) and on calciumphosphorus product (broken line). 
IRRADIATED EVAPORATED MILK IN INFANT FEEDING 301

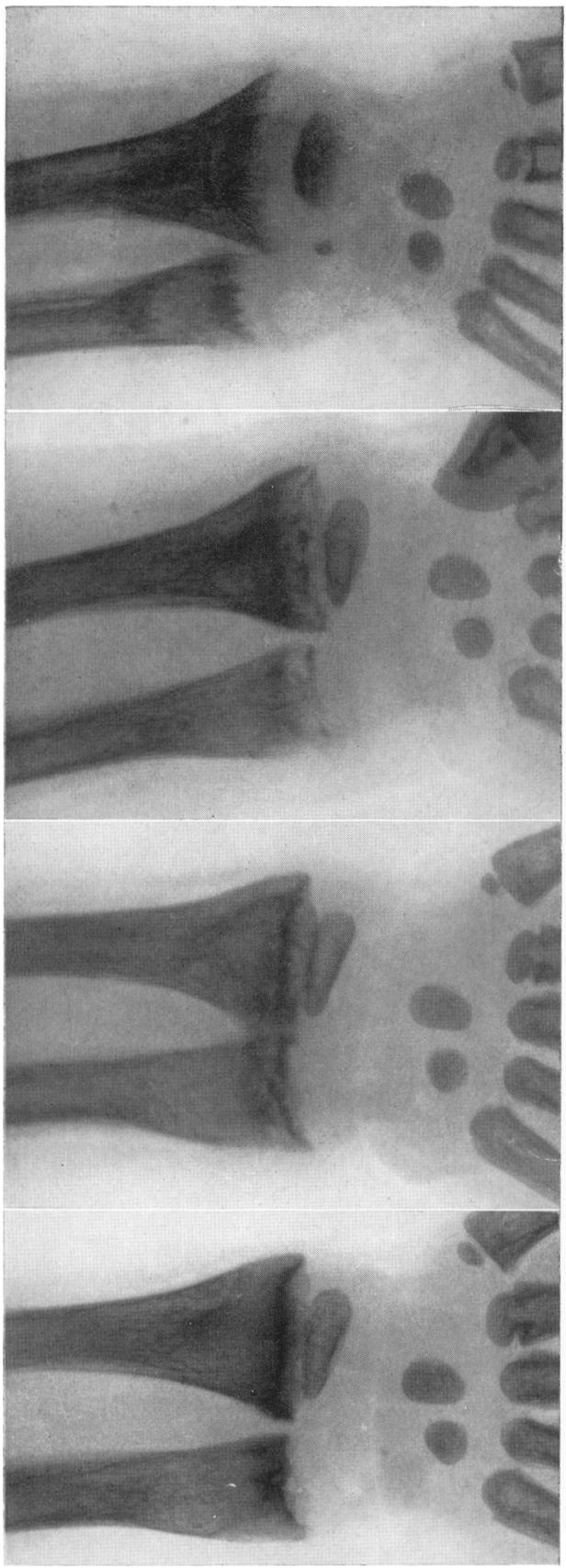

Fig. 2.-Case 1. B. D.

I : March 29, 1939. II : April 19, 1939. III : April 26, 1939. IV : May 11, 1939.

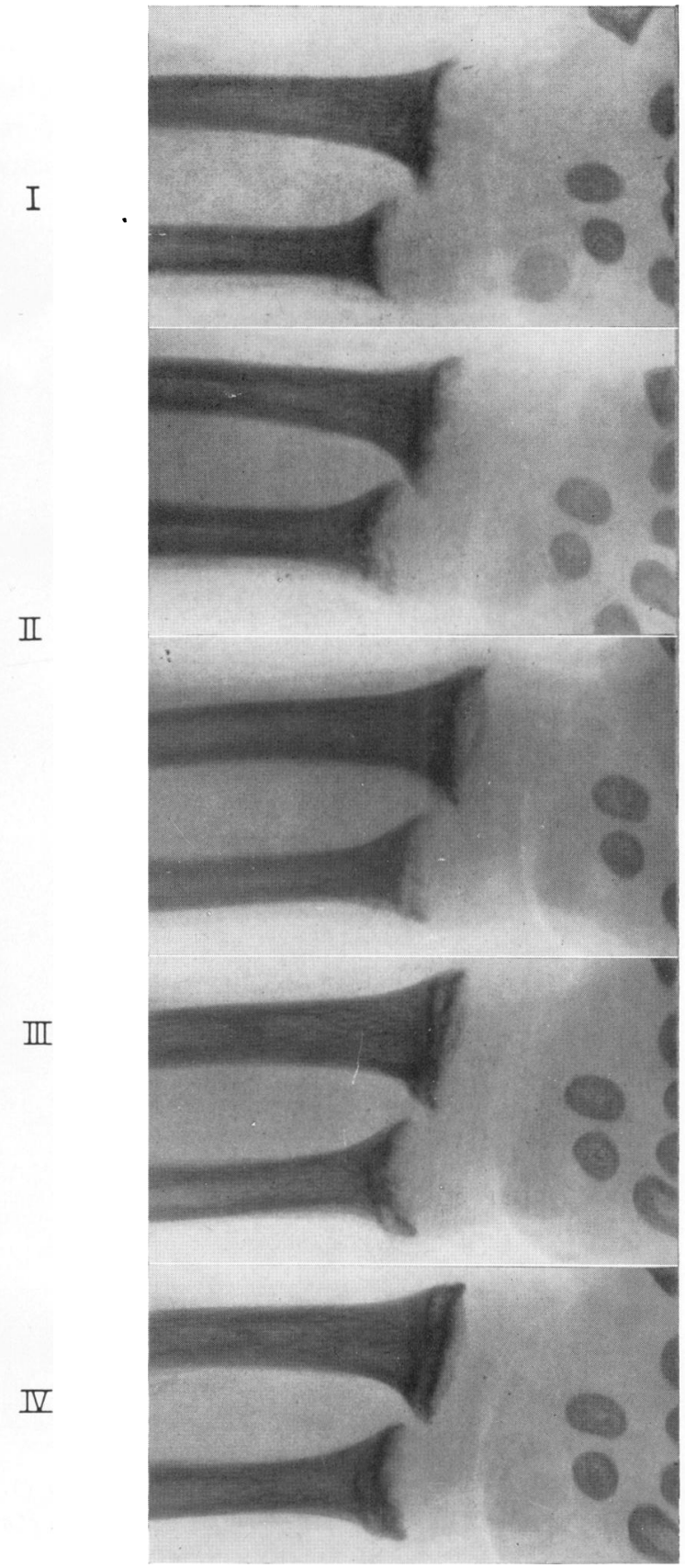

III

IV

FIG. 3.-Case 2. B. P.

I : May 8, 1939. II : May 15, $1939 . \quad$ III : May 22, 1939. IV : May 30, 1939. V : June 5, 1939. 
some slight coincident calcification present at the metaphysis of the wrist. Serial $x$-rays of the right wrist of cases 1 to 6 are illustrated in fig. 2 to 7 . Case 7 showed less marked cupping than the other cases, but mild active rickets before treatment was started, and increased regularity of the metaphyseal line and calcification in four weeks. After treatment with irradiated milk, every

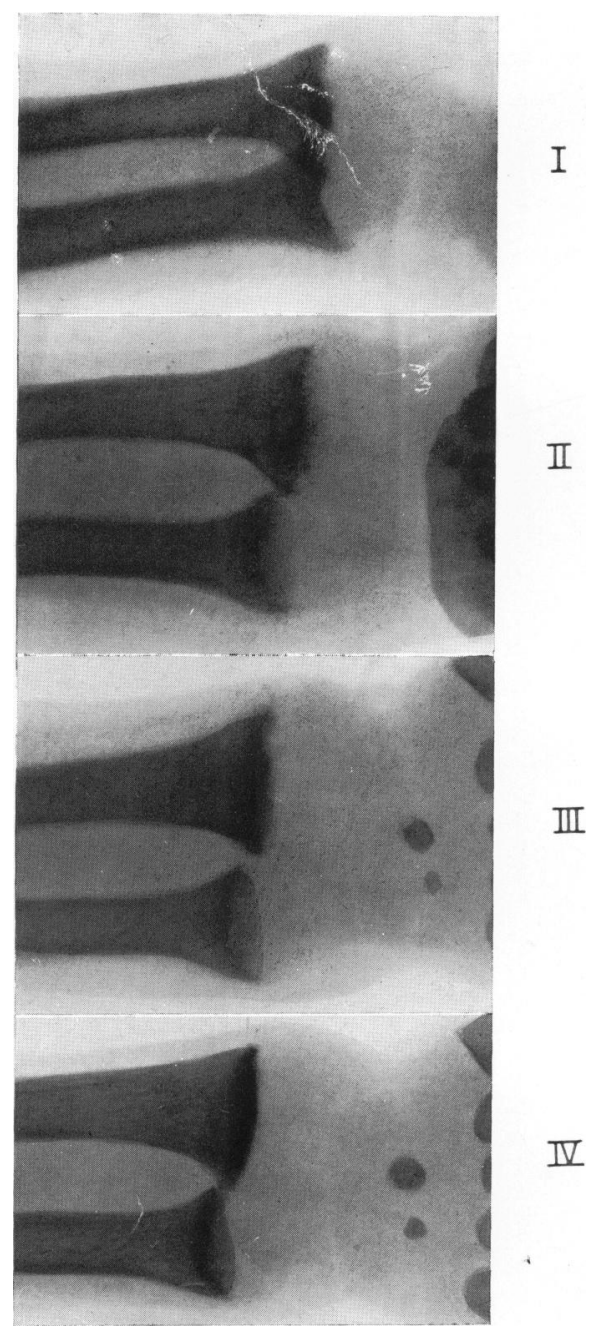

Fig. 4.-Case 3. R. W.

I : April 28, 1939. II : May 5, 1939. III : May 15, 1939. IV : June 5, 1939.

case shows clear evidence of progressive healing. This became recognizable in from one to three weeks, and in all cases had become well advanced in four to five weeks. The impression was gained, however, from case 1, which was kept under observation for a period of ten weeks, that there was little progress in the healing process after about six weeks, and that at the end of 

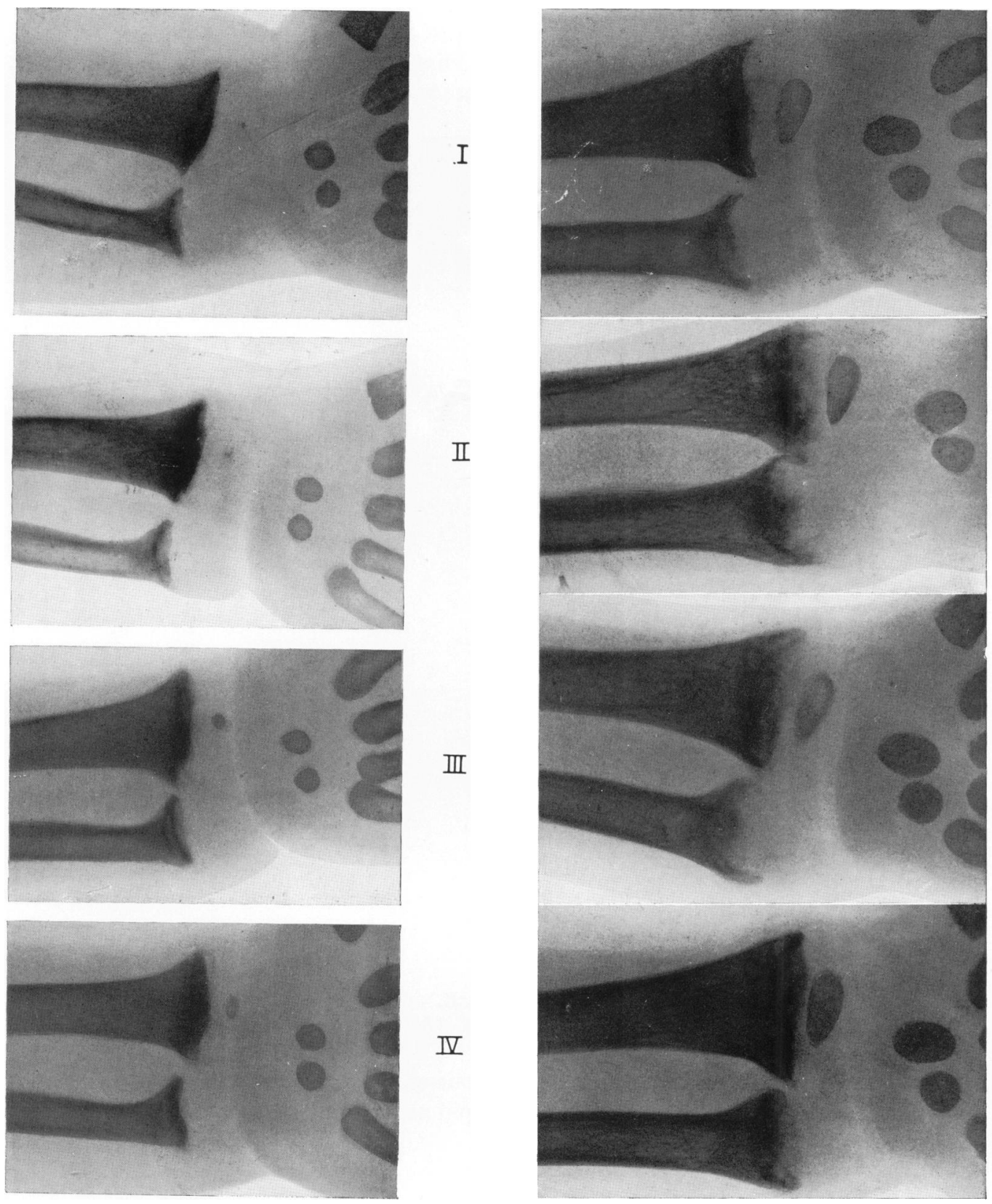

II

Fig. 5.-Case 4. P. J.

Fig. 6.-Case 5. I. G.

I : April 12, 1939. II : April 21, 1939. III : May 3,1939. IV : May 17, 1939.

I : March 25, 1938. II : April 1, 1938. III : April 8, 1938. IV : April 30, 1938. 
the period of observation calcification was less perfect than in a control case of the same age treated with 15 minims of adexolin daily, ultraviolet light and a more normal diet. It is clear, therefore, that in this group of older infants suffering from active rickets, treatment with irradiated evaporated milk without other source of vitamin D was sufficient to initiate healing which was progressive

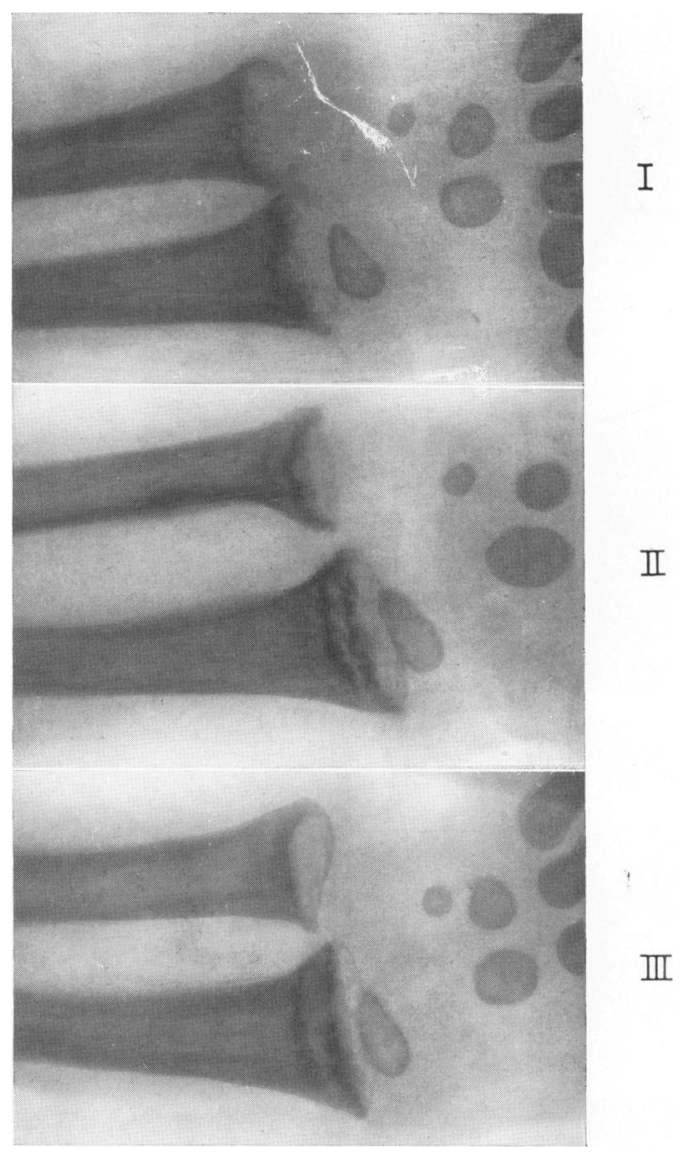

Fig. 7.-Case 6. A. R.

I : February 3, 1938. II : February 28, 1938. III : March 10, 1938.

for at least four to five weeks. It is not, of course, suggested that this method of treatment alone provides either the most rapid or perfect means of cure.

\section{Discussion}

The results obtained in the normal group of infants treated as out-patients during the winter and spring indicate that whilst irradiated evaporated milk of this potency may serve as a prophylactic against rickets in the majority of cases, it is not completely reliable for this purpose and that mild rickets may develop during its administration. Study of the rachitic group, on the other 
hand, showed that its anti-rachitic properties were sufficient to initiate healing in every case. The apparent anomaly that the milk was sufficient to cure but not to prevent rickets is probably largely explicable by the age of the patients in the two groups. Thus in the case of the older rachitic infants, it was (after the first few days) possible to administer a larger total quantity of milk than to the younger infants, whilst the vitamin $\mathrm{D}$ requirements are relatively greater during the period of rapid growth in the first year than subsequently. It has also been shown experimentally, however (Bethke, Kennard, and Sassaman, 1927), that amounts of vitamin D insufficient for the prophylaxis of rickets in rats may produce some degree of calcification in rachitic rats on the same diet. There is known to be a considerable individual variation in the tendency to develop rickets, even in cases in which the experimental conditions can be controlled much more strictly than is possible in an out-patient study. The fact that a small percentage of these cases developed rickets whilst the majority remained free is therefore not surprising. It does, however, suggest that in the rickets-free patients the dosage of vitamin D approached the lower limit of safe protection. Jeans and Stearns (1934) have shown that whilst such a dosage may prevent manifest rickets, it may still fall short of the optimum for requirements for growth and calcification.

Although prematures were not included in the present study, Davidson et al. (1937) and others have shown conclusively that prematures are in much greater danger of developing rickets on irradiated evaporated milk than are full-term babies. This is due both to their more rapid growth and to the smaller total quantity of milk they are able to consume daily, although the number of units of vitamin D per kilogramme body-weight may be practically the same as that of full-term infants.

\section{Summary and Conclusions}

(1) Twenty normal full-term infants were given irradiated evaporated milk as their sole source of oral vitamin D during three to six months between October and April. At the end of three months one infant showed radiological evidence of mild active rickets and two of healed rickets.

(2) Seven infants suffering from active rickets were treated as in-patients with irradiated evaporated milk as their sole source of vitamin D. Evidence of healing was seen in all cases in from one to three weeks.

(3) It is concluded that although the brand of irradiated evaporated milk used will serve to protect the majority of full-term infants from manifest rickets, it cannot be relied on to do so in all cases.

(4) That the milk in question has considerable anti-rachitic properties is shown by the response of the rachitic group of infants. It should therefore serve as a valuable source of vitamin $D$, particularly in the case of infants who receive vitamin D supplement irregularly or in insufficient amount. The milk should not, however, be relied on as the sole source of vitamin D, particularly in the case of prematures.

(5) The milk was found easy to use, and was taken well by the great majority of infants. No ill effects were observed from its prolonged administration. 
Thanks are due to Dr. H. M. Worth, Dr. L. J. Rae, and Miss Phillips for the radiological examinations ; Dr. A. Signy for the biochemical estimations; Miss Boulting and Miss Obery for supervision of infants attending the Barley Mow welfare centre and Sister Opie and Sister Lowe for their co-operation in treating the ward cases. The milk used in this investigation was kindly supplied by General Milk Products, Ltd.

\section{REFERENCES}

Bethke, R. M., Kennard, D. C., and Sassaman, H. L. (1927). J. biol. Chem., 72, 702. Cowell, S. J. (1925). Brit. med. J., 1, 594.

Davidson, L. T., Merritt, K. K., and Chipman, S. S. (1937). Amer. J. Dis. Child., 53, 1. Eliot, M. M., and Powers, G. F. (1935). J. Amer. med. Ass., 102, 1823.

Hess, A. F., and Lewis, J. M. (1932). Ibid., 99, 647.

- (1933). Ibid., 101, 181.

Hess, A. F., and Weinstock, M. (1924). J. biol. Chem., 62, 301.

Jeans, P. C. (1936). J. Amer. med. Ass., 106, 2066, 2150.

Jeans, P. C., and Stearns, G. (1934). Proc. Soc. Exp. Eiol. N.Y., 31, 1159.

Nabarro, D., and Hickman, J. O. (1929). Lancet, 1, 127.

Steenbock, H., and Black, A. (1924). J. biol. Chem., 62, 301.

Steenbock, H., and Daniells, A. L. (1925). J. Amer. med. Ass., 84, 1093.

Watson, C., Finlay, T. Y., and King, J. B. (1929). Lancet, 2, 1090. 